\title{
Correction to: KReC-MD: Knowledge Revision with Multiple Documents
}

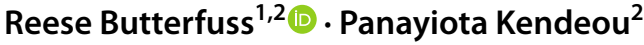

Published online: 30 October 2021

(c) Springer Science+Business Media, LLC, part of Springer Nature 2021

\section{Correction to: Educational Psychology Review https://doi.org/10.1007/s10648-021-09603-y}

The originally published version of this article contained mistakes and the author would like to correct them.

In the right panel of Fig. 1, the gray circles representing source credibility of the example sources were mislabeled as "high" credibility. The correct labels should indicate "low" credibility because those sources (Fox News, Buzzfeed, and Huffington Post) are relatively low credibility compared to the sources included in the left panel. The corrected image appears as follows:
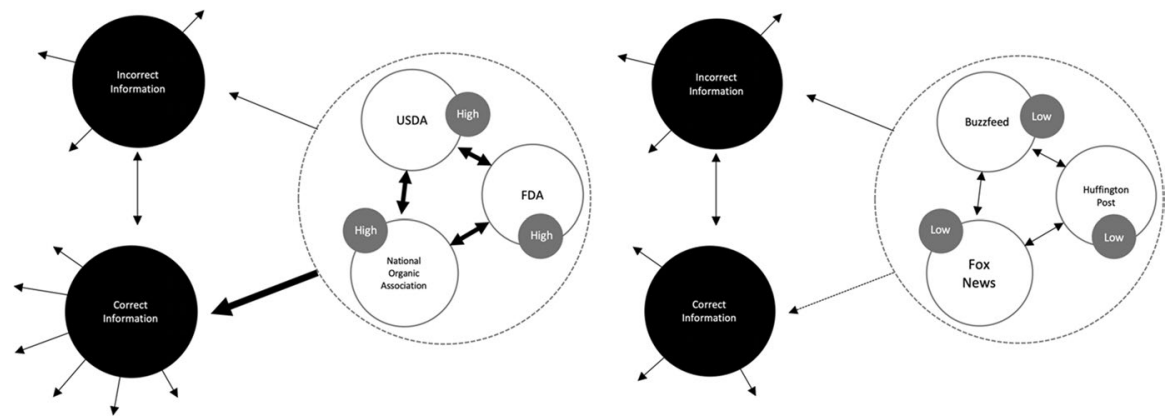

Fig. 1 KReC-MD Documents model in scenario 1: high-credibility sources (left) and scenario 2: lowcredibility sources (right). Black circles represent concepts in the situations model. The large dotted circle represents the intertext model, and smaller white circles represent the documents. Gray circles represent source credibility tags. Double-headed arrows represent source-source links. Single-headed arrows represent intertext links

The original article can be found online at https://doi.org/10.1007/s10648-021-09603-y.

Reese Butterfuss

rmbutterfuss@gmail.com

1 Department of Psychology, Arizona State University, 950 S. McAllister Ave, Tempe, AZ 85287 , USA

2 Department of Educational Psychology, University of Minnesota, Minneapolis, MN, USA 
The original article has been corrected.

Publisher's Note Springer Nature remains neutral with regard to jurisdictional claims in published maps and institutional affiliations. 